\title{
Surgical Management of a Traumatic Paraplegic with Severe Myositis Ossificans Bilateral Hip: A Case Report
}

Tarun Chabra $^{1^{*}}$, Jayaramaraju Dheenadhayalan ${ }^{2}$ and Shanmuganathan Rajasekaran ${ }^{2}$

FNB Trauma Care Center, Department of Orthopaedics, Ganga Medical Center and Hospital, Coimbatore, India

"Corresponding author: Tarun Chabra, FNB Trauma Care Center, Department of Orthopaedics, Ganga Medical Center and Hospital, Coimbatore, India, Tel: +919599127021; Fax: +9101662245020; E-mail: tarunkchabra@gmail.com

Rec Date: February 26, 2018; Acc Date: March 19, 2018; Pub Date: March 24, 2018

Copyright: (c) 2018 Chabra T, et al. This is an open-access article distributed under the terms of the creative commons attribution license, which permits unrestricted use, distribution, and reproduction in any medium, provided the original author and source are credited.

\begin{abstract}
We report a case of 42-year-old male traumatic paraplegic (D9 level, ASIA A) with inability to sit in the bed and wheelchair which interfered in his rehabilitation because of myositis ossificans at bilateral hips which was confirmed clinically and radiologically. He underwent excision arthroplasty bilateral hips following which his sitting restored and patient independently used wheelchair and successfully earned his livelihood.
\end{abstract}

Keywords: Excision arthroplasty; Myositis ossificans; Paraplegic

\section{Introduction}

Myositis ossificans was first described by Patin in 1962 in a child with myositis ossificans progressive [1]. Myositis ossificans is a benign reactive proliferative lesion which occurs in soft tissues and it is usually secondary to trauma, extensive burns, immobilization due to coma and traumatic paraplegia. It occurs in muscles usually, but it can involve tendons and even subcutaneous fat, most commonly found in quadriceps, gluteal, brachialis and small muscles of hand because they are subjected to direct or indirect injury [2]. During First World War it was observed that gun-shot spinal injured patients had more incidence of myositis and at that time relation was found between edema and traumatic lesions of the nervous system [3]. The pathophysiology of myositis ossificans is very complex and not well understood, it follows the injury as it triggers osteo-inductive factors that activates the chondrocyte and osteoblast progenitor cells and activates osteogenesis [4]. The incidence of MO in spinal cord injured patient is $20 \%$ to $25 \%$
[5], neurogenic myositis ossificans mainly affects large joints like hip and it is very debilitating condition which can cause vascular or neural compression and can adversely affects the patient rehabilitation.

\section{Case Report}

A 42-year-old male paraplegic patient had road traffic accident one year back following which patient had traumatic spinal cord (ASIA A neurology) contusion at D9 level, head injury and bilateral shaft humerus fracture for which D9 laminectomy and interlocking nailing done after 3 days of the accident. He had bilateral lower limb stiffness and was diagnosed as myositis ossificans bilateral hip and during physiotherapy he had fracture shaft femur for which interlocking was done 2 months after the first surgery. After 4 months of $2^{\text {nd }}$ surgery he developed grade bed sores over the gluteal region and grade 3 bed sores over left infra-trochanteric region for which debridement and rotation flap for sacral sore was done. Patient presented to orthopedic outpatient department with chief complaint of inability to sit in the bed and wheel chair.
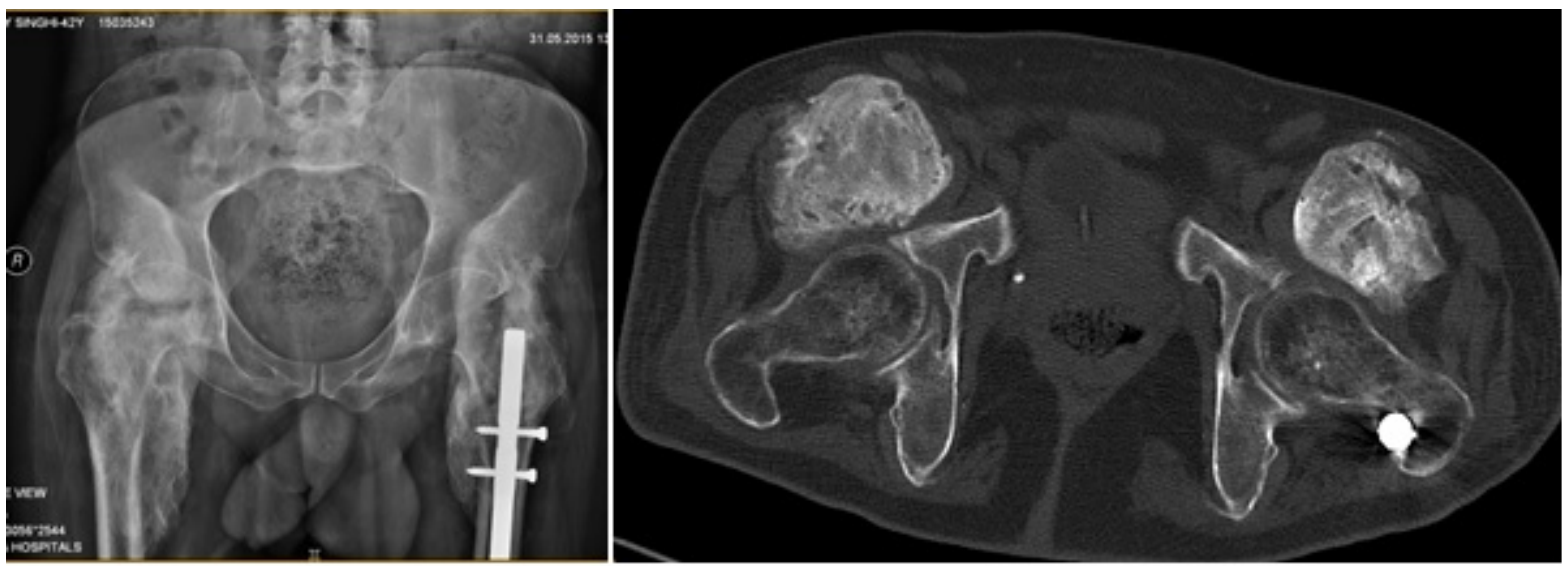

Figure 1: X-ray and CT pelvis shows myositis ossificans mass at both hips. 
Citation: Chabra T, Dheenadhayalan J, Rajasekaran S (2018) Surgical Management of a Traumatic Paraplegic with Severe Myositis Ossificans

On examination both the hips were fixed in neutral position and bony mass was palpable over both the hips medially, anteriorly and laterally. Healed scars over sacral and left thigh and right lateral malleolar area were present. Both the knees had significant stiffness (only 5 to 10-degree flexion was possible in both knees). Complete sensory and motor loss below D10 level with bladder and bowel involvement. X-ray pelvis including both hips showed heterotrophic ossification mass over both hips (Figure 1).

CT pelvis showed large irregular lobulated soft tissue heterotrophic ossification over bilateral hip joints extending from medial anteroinferior iliac blade up to medial aspect of proximal femur diaphysis measuring $18 \times 7 \times 6.3 \mathrm{~cm}(\mathrm{CC} \times \mathrm{ML} \times \mathrm{AP})$ on right side and $17 \times 5 \times$ $5.2 \mathrm{~cm}(\mathrm{CC} \times \mathrm{ML} \times \mathrm{AP})$ on left side and fracture with complete nonunion of shaft of proximal femur with intramedullary nail in situ.

We planned for staged procedures first left and then right hip myositis mass excision and excision arthroplasty was performed. Under general anesthesia, in supine position using anterior smith Peterson approach myositis mass extending from iliac crest to proximal femoral shaft was exposed and myositis mass was excised in pieces while protecting the femoral vessels, hip joint exposed, capsule cut and femoral head osteotomized at its base and removed, hemostasis achieved, and bleeding bone surfaces covered with bone wax (Figures 2 and 3).

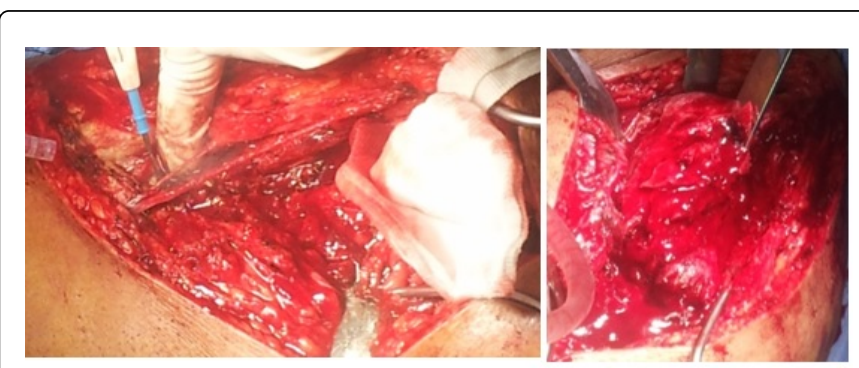

Figure 2: Exposure through smith Peterson approach and excision of myositis mass at left hip.

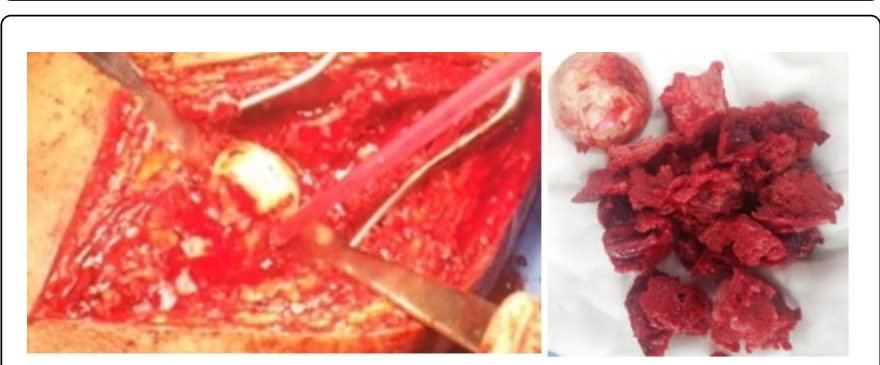

Figure 3: Excision of the femoral head and myositis mass.

Wound packed with gel foam and closure in layers with drain. Patient was admitted to ICU after right side procedure because he had around 2.5 liters blood loss during the surgery, patient shifted in ward after 2 days and his rehabilitation was started (Figure 4).

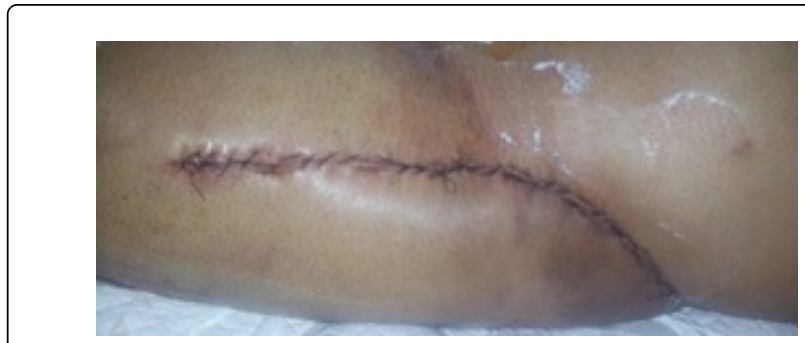

Figure 4: Closure of surgical wound.

Post-operative rehabilitation program included deep vein thrombus prophylaxis pumps, bilateral skin traction $(3 \mathrm{~kg})$, log rolling every 2 hours, back care, continuous passive motion for both knees which was gradually increased to 110 degrees, passive range of motion exercises for hip twice daily. On $3^{\text {rd }}$ day patient was able to sit in the bed and on $10^{\text {th }}$ day patient was transferred to wheel chair and wheel chair training started. Patient was comfortable in wheel-chair and he was back to his job with regained confidence (Figures 5 and 6).

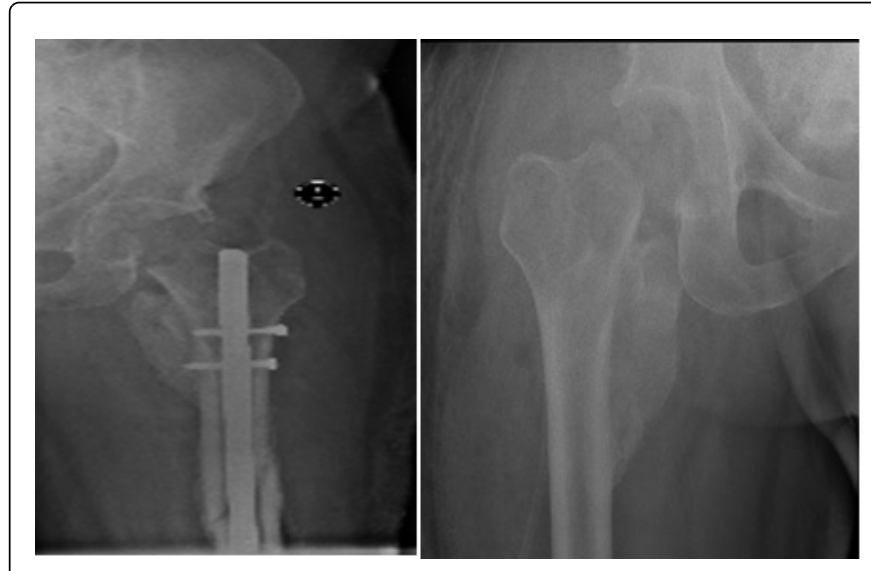

Figure 5: Post-operative X-rays of the patient after excision arthroplasty.

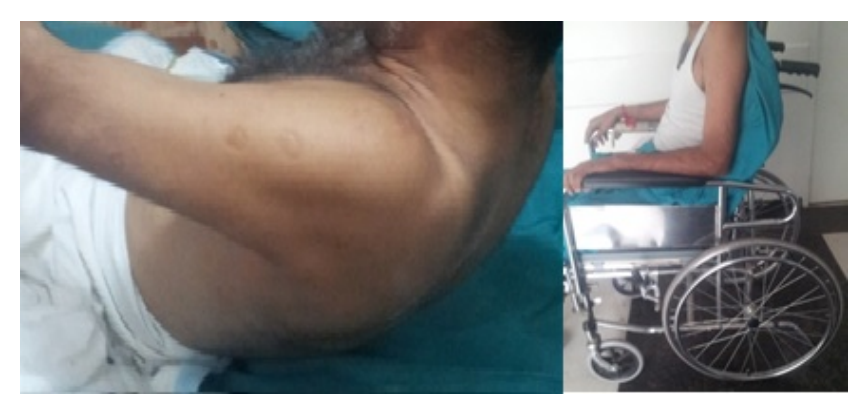

Figure 6: Comparison of pre-operative and post-operative condition of the patient. 
Citation: Chabra T, Dheenadhayalan J, Rajasekaran S (2018) Surgical Management of a Traumatic Paraplegic with Severe Myositis Ossificans

Page 3 of 3

\section{Discussion}

Myositis ossificans is a frequent complication in a spinal cord injury patient. In $20 \%$ to $30 \%$ of spinal cord injured with myositis patients presents as reduction in joint range of motion while only $3 \%$ to $8 \%$ presents with ankylosis [6,7]. It always involves part below the level of spinal injury and commonest site is the hip joint but other segment can be involved like spine, hand, shoulder, elbow and the knee (in increasing incidence) $[8,9]$. Due to spasticity of limb and reduced movement at hip there is great difficulty in sitting, halts transfers which can lead to pressure sores and compromises daily living [10,11] Although there are many ways of prevention like drug treatment and radiation therapy but in already formed bone surgery is the only solution but along with chances of complications like deep venous thrombosis, infections, pressure ulcers and major blood loss are there [12].

\section{Conclusion}

Surgical resection of myositis ossificans mass along with excision arthroplasty in a debilitated paraplegic patient with bilateral hip myositis mass is the solution for prevention of sores, spasms and early rehabilitation. However, complications like infection, intra-operative bleeding and postoperative hemorrhage should be kept in the mind before performing surgery.

\section{References}

1. Geschickter CF, Maseritz I (1938) Myositis ossificans. J Bone Joint Surg Am 20: 661-674.

2. Campanacci M (1990) Bone and joint soft tissue tumor. SpringerVeralg,Vienna pp: 821-830.

3. Damanski M (1961) Heterotopic ossification in paraplegia: A clinical study. Bone Joint J 43: 286.

4. Chalmers J, Gray DH, Rush J (1975) Observation on the induction of bone in soft tissues. J Bone Joint Surg Br 57: 36-45.

5. Garland DE (1991) A clinical perspective on common forms of acquired heterotopic ossification. Clin Orthop 263: 13-29.

6. Hardy AG, Dickson JW (1963) Pathological ossification in traumatic paraplegia. J Bone Joint Surg 45: 76-87.

7. Freehafer AA, Yurick R, Mast WA (1966) Para-articular ossification in spinal cord injury. Med Serv J Can 22: 471- 478.

8. Bravo-Payno P (1992) Incidence and risk factors in the appearance of heterotopic ossification in spinal cord injury. Paraplegia 30: 740- 745.

9. Buschbacher R (1992) Warfarin in prevention of heterotopic ossification. Am J Phys Med Rehabil 71: 86-91.

10. Roche MB, Jostes FA (1948) Ectopic bone deposits. Aparaplegic complication. Am J Surg 75: 633-636.

11. Garland DE (1991) A clinical perspective on common forms of acquired heterotopic ossification. Clin Orthop Relat Res 263: 13-29.

12. Meiners T, Abel R, Bohm V, Gerner HJ (1997) Resection of heterotopic ossification of the hip in spinal injured patients. Spinal Cord 35: 443-445. 